\title{
A High-Frequency, Shallow-Water Acoustic Measurement System
}

\author{
STEVE STANIC, BRUCE E. ECKSTEIN, ROBERT L. WILLIAMS, PETER FLEISCHER, AND KEVIN B. BRIGGS
}

\begin{abstract}
The Naval Ocean Research and Development Activity has developed a new high-frequency acoustic measurement system for use in shallow water. The heart of this system is a pair of submersible towers supporting acoustic transmitting and receiving instrumentation. These towers are transported to an experimental staging area, assembled, and acoustic instrumentation installed. They are towed to a pre-selected measurement site, then the chambers on each tower are flooded, thereby settling slowly to the ocean bottom. Stability and dynamic response analyses were used to determine the towing and deployment stability envelopes for the towers. The acoustic transmitting system uses a pair of narrow-beam parametric acoustic sources operating at secondary frequencies ranging from 20 to $180 \mathrm{kHz}$. The acoustic receiving systems consist of a pair of 16 hydrophone, two-dimensional arrays with broadband capabilities up to $250 \mathrm{kHz}$. These systems have been used to make high-resolution bottom scattering measurements in shallow water off the coast of Florida.
\end{abstract}

\section{INTRODUCTION}

I N GENERAL, the acoustic characteristics of signals, noise, and reverberation in the deep ocean differ significantly from those in shallow or narrow coastal areas. The proximity of boundaries, increased substrate and water-column inhomogeneity, and increased density or influence of noise sources contribute to the extreme complexity of shallow-water acoustic environments. In order to develop acoustic systems that can operate effectively in shallow water, an understanding of the interaction of the environmental and acoustic parameters must be obtained.

Over the past several decades considerable effort has been directed towards understanding the effects of shallow-water, high-frequency ocean boundary scattering [1]-[3]. Early measurements were obtained using sources and receiving hydrophones deployed from research ships. The results were always contaminated by ship and source-receiver motions. Recent measurements have been made using transducers mounted on tripod-like structures placed on the ocean bottom and hardwired to a support ship or research tower [4]-[6]. While source-receiver motions were eliminated, these instrumentation systems could only be deployed in calm seas using ships with moderate capacity cranes.

Since the ocean bottom is a major factor in the shallow water environment, the Naval Ocean Research and Development Activity (NORDA) established a program that focuses

Manuscript received July 13, 1987; revised March 22, 1988. This work was supported by the Naval Ocean Research and Development Activity, NORDA Contribution Number 240:020:87.

The authors are with the Naval Ocean Research and Development Activity of the National Space Technology Laboratory, MS 39529.

IEEE Log Number $\mathbf{8 8 2 1 8 2 9 .}$ on the relationships between ocean bottom properties and acoustic scattering. The experimental program consists of an integrated series of acoustic and environmental measurements designed to identify and isolate various bottom-scattering mechanisms, and to resolve their effects on acoustic back- and forwardscattered fields. Data from these measurements are serving as a basis for developing shallow-water environmental acoustic models for use in exploratory and advanced development programs.

In order to accomplish the goals of this program NORDA developed a novel method of deploying acoustic instrumentation on the ocean bottom. Using expertise available in the Louisiana offshore oil industry, NORDA and Petro-Marine Engineering of Gretna, Louisiana, designed and constructed two shallow-water acoustic instrumentation towers (Fig. 1). One tower contains a high-frequency acoustic transmitting system and a system to receive signals backscattered from the bottom. The second tower contains a system to receive forwardscattered signals. These towers have been used to conduct acoustic bottomscattering experiments in shallow waters off the coast of Florida. Acoustic scattering measurements were made as a function of frequency $(20$ to $180 \mathrm{kHz})$, grazing angle $\left(5\right.$ to $30^{\circ}$ ), and environmental conditions.

\section{Acoustic Instrumentation Towers \\ A. Tower Design}

Each tower is a twin-hull catamaran with a vertical tank supporting an electronic instrumentation chamber, a triaxial positioning system, and a two-dimensional array mount. The array mount is a rigid tubular support structure for acoustic sources and receiving hydrophones. The sources and receiving arrays are aimed using the remotely controlled triaxial positioner. Each tower can be dissassembled for transportation to an experimental staging area. The major subassemblies are shown in Fig. 2.

The two pontoons of the catamaran hull have a length of 35 feet and a diameter of 48 inches. The center section of each pontoon is a sealed buoyancy chamber that is structurally reinforced by two watertight bulkheads. These chambers form part of the subsurface buoyancy system. The two pontoons are connected together by a sealed bridge structure that is 22 feet in length and 7 feet in width, constructed from 12-inchdiameter steel pipe.

The fourth major subassembly is a 12 -ft high, 60-inchdiameter vertical tank section. The upper 8 feet comprise a sealed buoyancy chamber and the lower 4 feet a variable buoyancy section. This lower section and the ballast chambers 


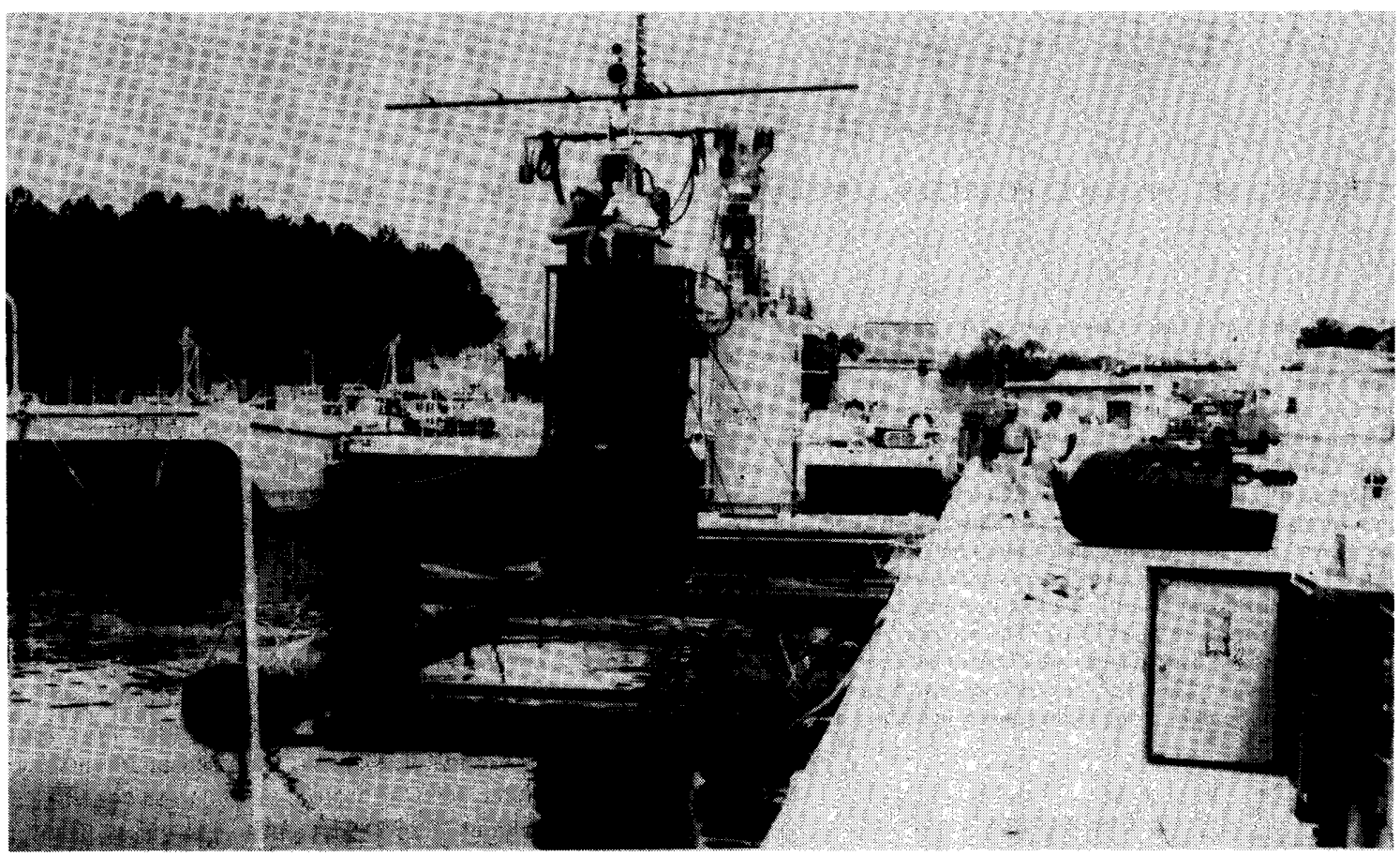

Fig. 1. NORDA's shallow-water acoustic measurement systems.

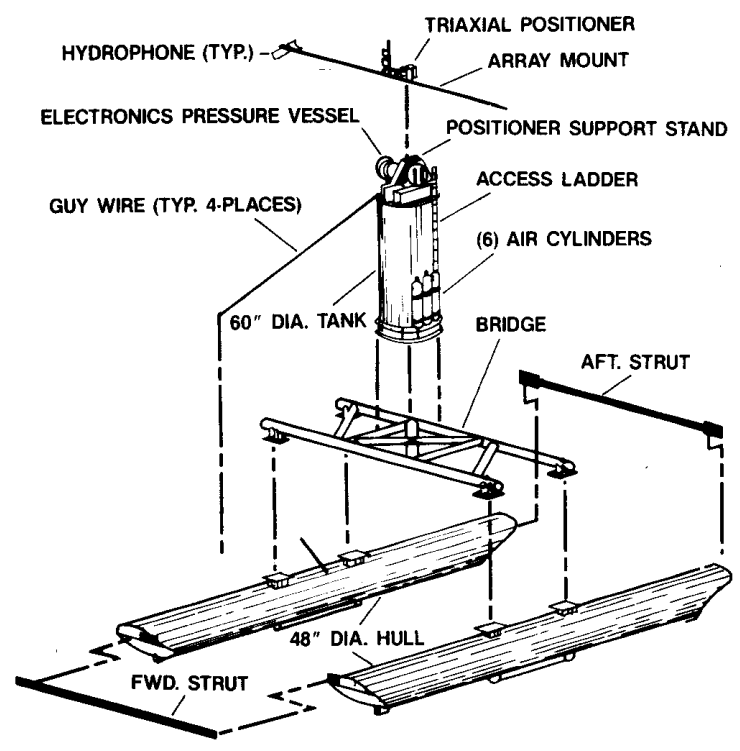

Fig. 2. Major tower subassemblies.

in the ends of the pontoons are filled with sea water for subsurface deployments (Fig. 3). Air from six high-pressure air cylinders mounted around the 60 -inch vertical tank tower (Fig. 4) is used to deballast the lower section of the vertical chamber, which raises the structure. A large ship-mounted compressor then deballasts the pontoons.

During the initial design phase stability and dynamic

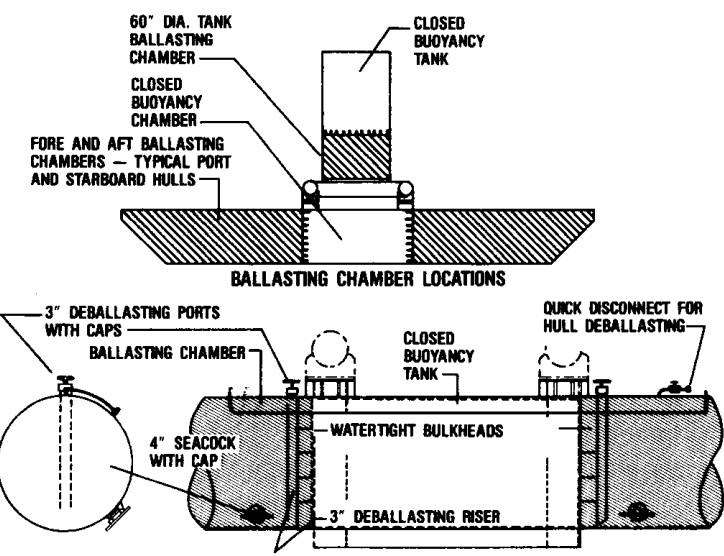

Fig. 3. Tower ballast/deballast systems.

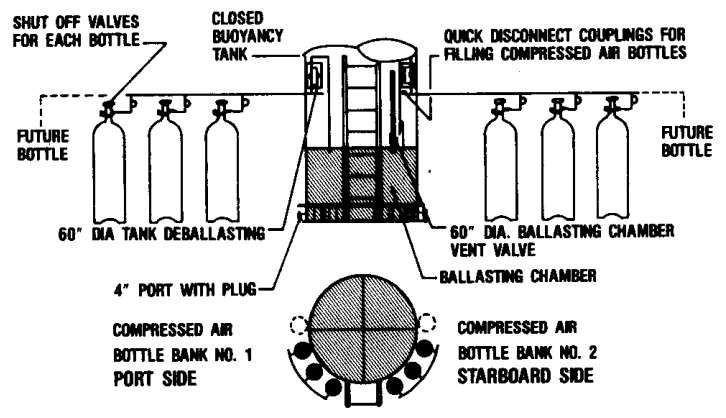

Fig. 4. Sixty inch diam. tank ballast/deballast system. 

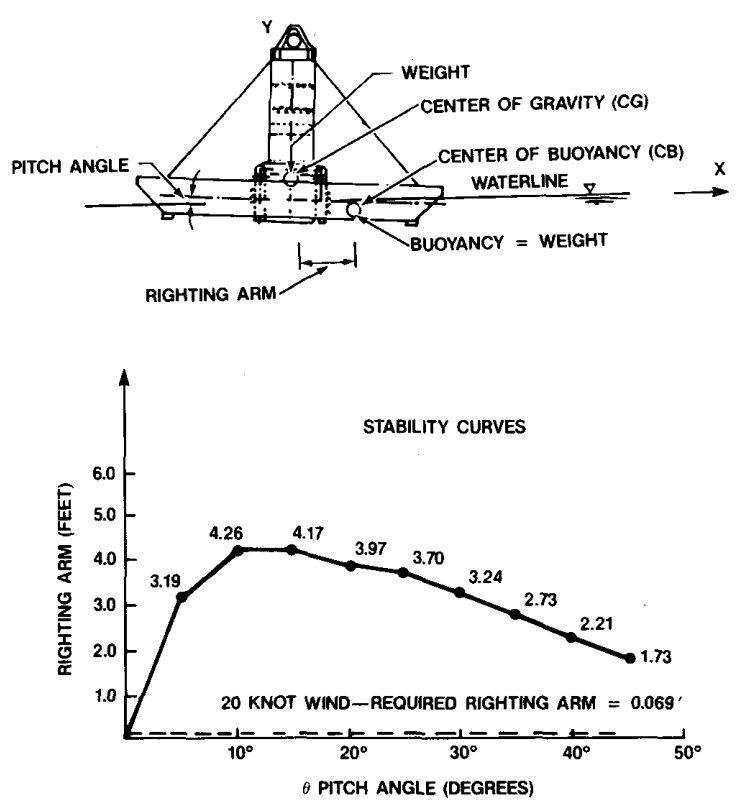

Fig. 5. Stability curve.

response analyses were conducted to examine tower responses during towing and submergence. The flotation stability curves shown in Figs. 5 and 6 were generated using DATEC's Flotation Analysis Program (FLOAT). This program solves for the theoretical equilibrium positions of a floating and submerged frame composed of pipe members. The option to partially flood selected members allows simulation of a complete static upending sequence to determine possible instabilities at intermediate flooding stages. The tower model was rotated $45^{\circ}$ to determine the stabilizing movements in the pitch-and-roll direction. The stability curves show changes in righting arm lengths with pitch-and-roll angles. At large pitchand-roll angles there is still a positive righting arm and the tower remains in a stable, upright configuration. The dashed line on each curve is the required righting arm for the overturning moments produced by a 20 -knot wind.

A dynamic response analysis was performed to determine maximum response of the tower during towing. The analysis was performed using the Ocean System Computer Analysis Routines (OSCAR) developed by Ultramarine, Inc. A frequency response analysis was made using a Pierson-Moskowitz sea-state spectrum for the sea state and tow conditions shown in Table $\mathrm{I}$.

The results of these analysis are given in Table II. The 1/ 100 response values are the average amplitudes (pitch angle, pitch acceleration, roll angle, roll acceleration, and heave acceleration) of the highest 1 percent of the dynamic response values for a particular sea state. This analysis shows that for a 5-foot sea the pitch-and-roll angles are within the righting arm stability envelopes given in Figs. 5 and 6.

\section{B. Tower Deployment and Recovery}

After a suitable experimental site has been chosen, a research vessel is placed in a four-point mooring. The typical
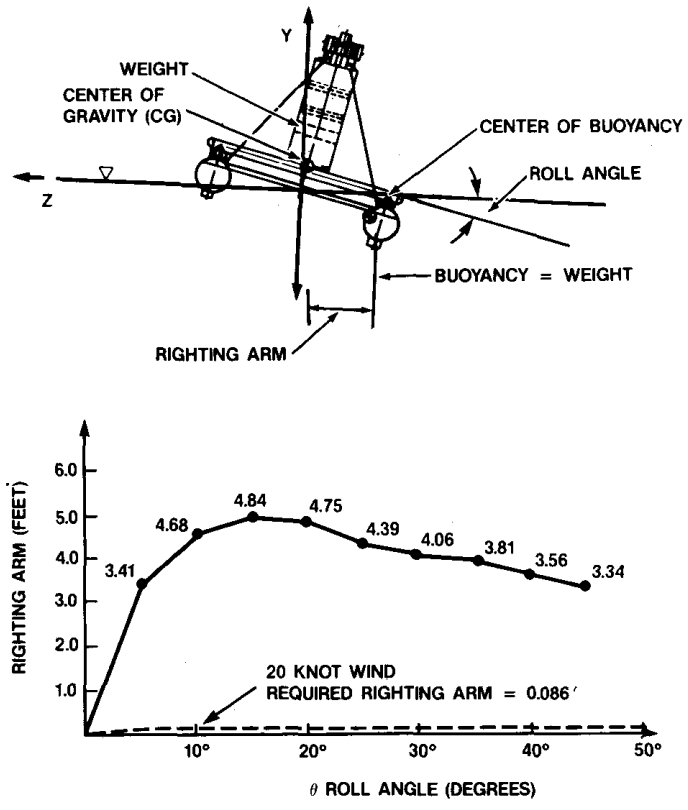

Fig. 6. Stability curve.

TABLE I

CONDITIONS FOR FREQUENCY RESPONSE ANALYSIS

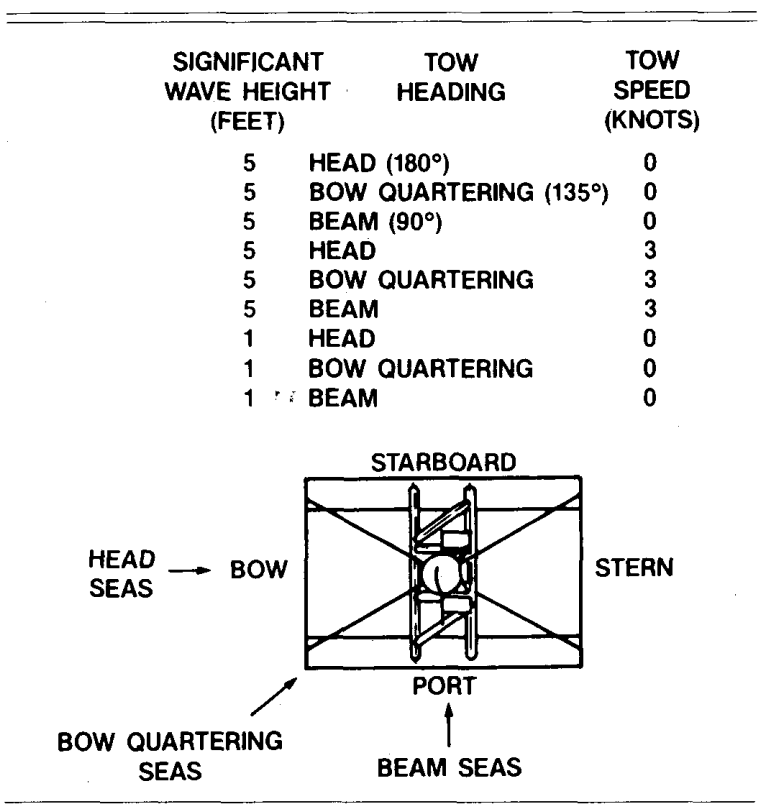

experimental configuration is shown in Fig. 7. Each tower is towed on the surface from a staging area to the experimental site. A schematic of the tower's deployment sequence is shown in Fig. 8. NORDA's scientific divers open ballast valves and 4-inch-diameter seacock caps on one pontoon. After 4 to 5 minutes the tower is in the position shown in Fig. 8(a). The second hull is then flooded, and after 15 to 20 minutes the 
TABLE II

PEAK DYNamic ReSPONSE (5 FT SigNIFICANT WAVE HeIGHT, 1/100 RESPONSES)

\begin{tabular}{|c|c|c|c|c|c|c|}
\hline \multirow[b]{2}{*}{$\begin{array}{l}\text { HEADING } \\
\text { (DEG) }\end{array}$} & \multirow{2}{*}{$\begin{array}{c}\text { TOW } \\
\text { SPEED } \\
\text { (KNOTS) }\end{array}$} & \multicolumn{2}{|c|}{ PITCH } & \multicolumn{2}{|c|}{ ROLL } & HEAVE \\
\hline & & $\begin{array}{l}\text { ANGLE } \\
\text { (DEG) }\end{array}$ & $\begin{array}{c}\text { ACCEL. } \\
\text { (DEG/SEC) }\end{array}$ & $\begin{array}{l}\text { ANGLE } \\
\text { (DEG) }\end{array}$ & $\begin{array}{c}\text { ACCEL, } \\
\text { (DEG/SEC) }\end{array}$ & $\begin{array}{l}\text { ACCEL. } \\
\text { (FT/SEC) }\end{array}$ \\
\hline 180 & 0 & 16.966 & 40.799 & - & - & 16.214 \\
\hline 180 & 3 & 13.666 & 19.198 & - & - & 8.122 \\
\hline 135 & 0 & 11.241 & 25.312 & 11.681 & 29.257 & 11.734 \\
\hline 135 & 3 & 9.751 & 17.401 & 11.092 & 21.250 & 8.553 \\
\hline 90 & 0 & - & - & 19.554 & 55.242 & 6.264 \\
\hline 90 & 3 & 3.201 & 5.283 & 19.593 & 55.262 & 7.679 \\
\hline
\end{tabular}

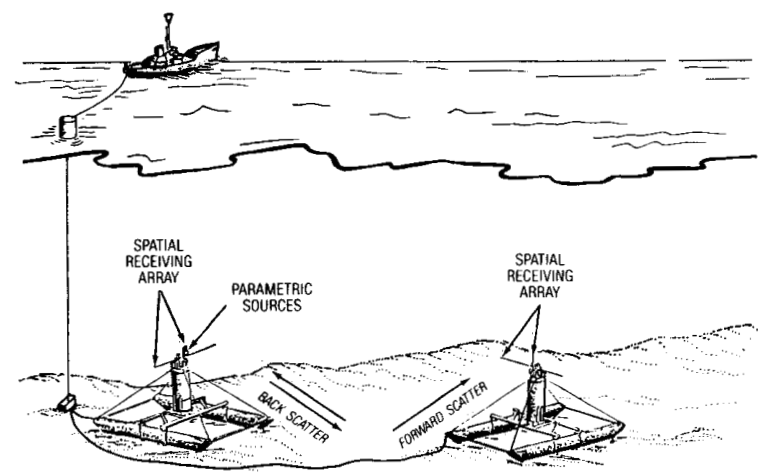

Fig. 7. Experimental configuration.
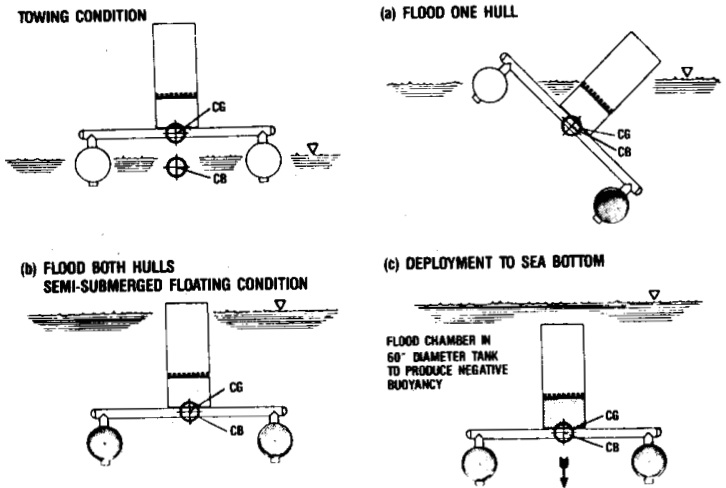

Fig. 8. Undersea deployment sequence.

tower is in the configuration shown in Fig. 8(b). In this position the structure is extremely stable and behaves as a spar buoy. The tower is now slowly towed to a marked position near the support ship. The two 4-inch-diameter seacocks are opened at the base of the 60 -inch-diameter tank. A vent valve then allows the variable buoyancy tank to flood, and the tower slowly settles on the ocean bottom. Divers then attach the source and receiving system electrical umbilical cables from the ship.

Each tower is refloated by first deballasting the lower section of the 60 -inch-diameter tank by using compressed air from the onboard air tanks. After deballasting the tower is returned to the stable spar buoy configuration. Each hull is then deballasted using a high-volume air compressor located on a small support boat. Each tower is then towed back to the staging port, disassembled, and returned to NORDA.
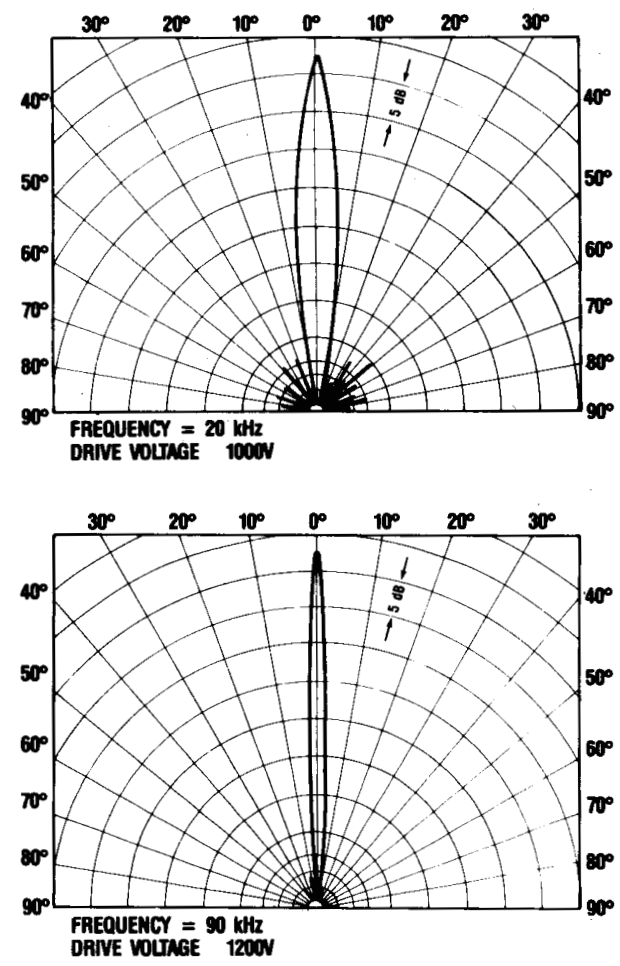

Fig. 9. Parametric beam patterns.

\section{Transmitting System}

Two broad-band parametric transducers are used to transmit acoustic signals over a frequency range from 15 to $180 \mathrm{kHz}$. The 6-inch-diameter source has a primary frequency of 250 $\mathbf{k H z}$ and transmits secondary frequencies between 20 and 90 $\mathrm{kHz}$. A second 12-inch-diameter source operates at a primary frequency of $450 \mathrm{kHz}$ and transmits secondary frequencies between 90 and $180 \mathrm{kHz}$. Typical beam patterns at 20 and 90 $\mathrm{kHz}$ are shown in Fig. 9. The transducers were designed and calibrated by the Naval Underwater Systems Center (NUSC), New London, Connecticut.

Fig. 10 is a schematic of the source transmitting and receiving $(T / R)$ system. The $T / R$ relay enables the scattered acoustic signals to be received conventionally on the $250 \mathrm{kHz}$ transducer. The signal mixer is a double sideband-suppressed carrier design. $F_{c}$ is the carrier frequency, $F_{d / 2}$ the difference frequency, and $F_{s}$ the sampling frequency. Both sources are aimed with a triaxial positioning system.

\section{ARRay ReCEIVING Systems}

Each tower supports identical receiving systems. These systems consist of the following major subsystems: a multihydrophone, two-dimensional spatial array; a triaxial positioning system; and a subsurface/shipboard data acquisition and computer system.

The receiving systems each utilize a two-dimensional spatial array. The arrays are 19 feet long and 3 feet high, arranged in a " $T$ " configuration. The hydrophones are EDO Model 6660 


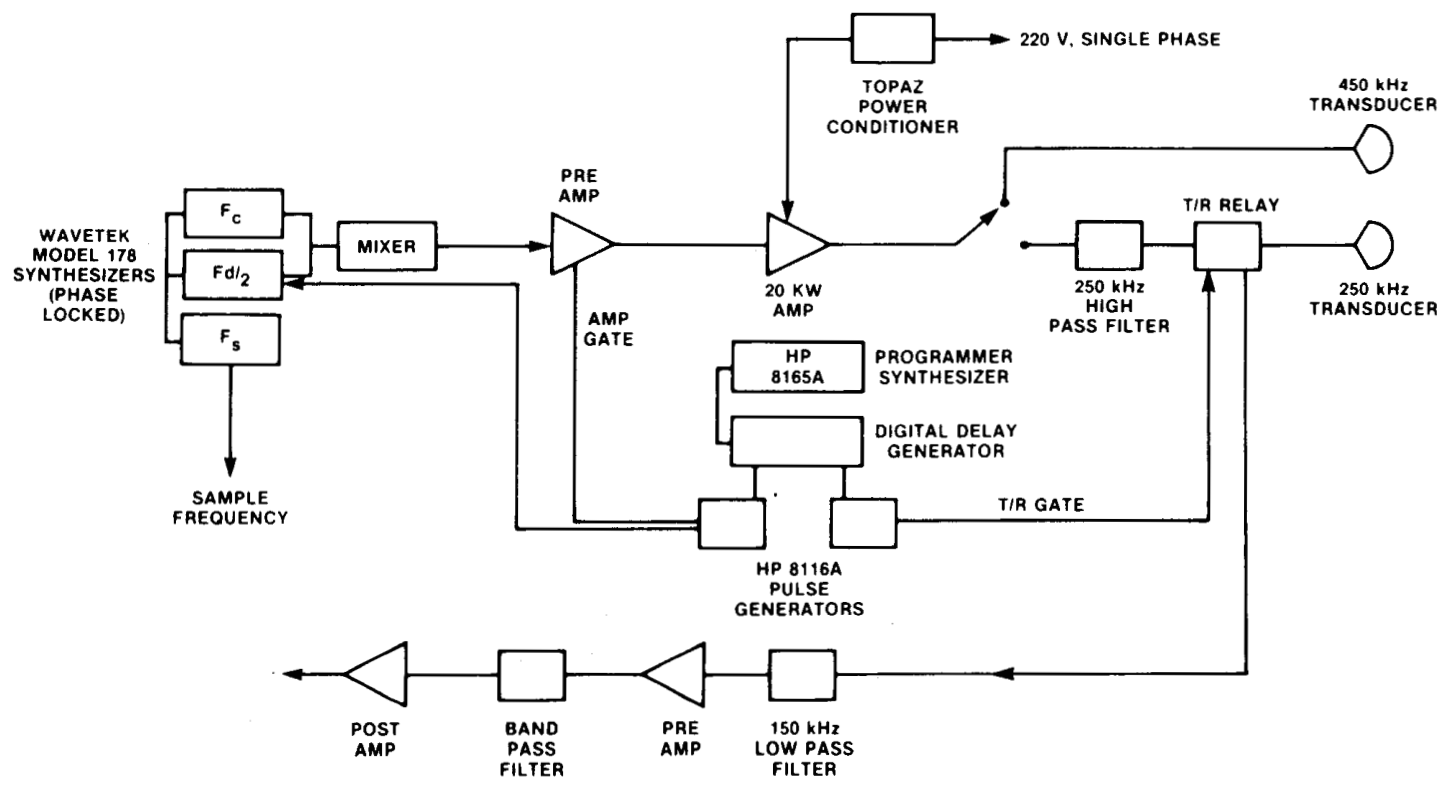

Fig. 10. Source transmitting and receiving systems.
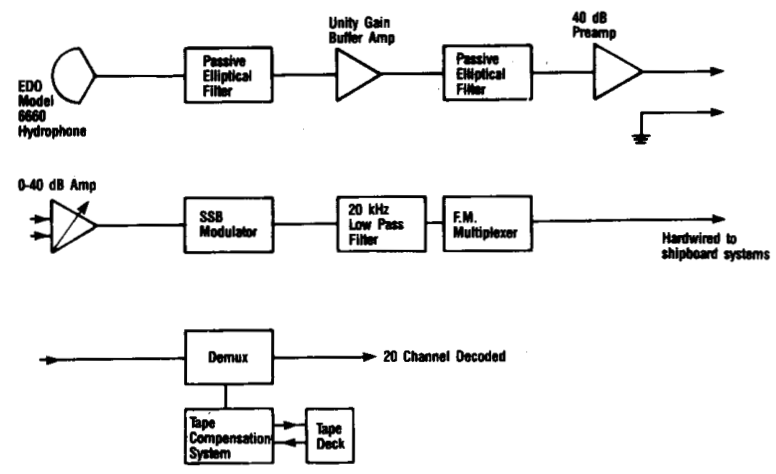

Fig. 11. Single channel configuration.

omnidirectional elements with broadband capabilities to 250 kHz. Fig. 11 shows a typical single channel configuration. The two elliptical filters, buffer amplifier, and 40-dB gain preamplifier are an integral part of each hydrophone. The filters are required to eliminate the high-level primary frequencies transmitted by the parametric sources. The output of each hydrophone is fed to the data acquisition and computer control system housed in the electronic containment vessel located atop each tower. The output from each of the 16 hydrophones is fed through a $40-\mathrm{dB}$ computer controlled variable gain amplifier, band shifted to $5 \mathrm{kHz}$, low pass filtered, and FM multiplexed with $80 \mathrm{kHz}$ spacing and $20 \mathrm{kHz}$ modulation. Engineering data on amplifier gain states, array position, time code, and modulator frequencies are included in the multiplexed signal. The total bandwidth of the multiplexed signal is $1.8 \mathrm{MHz}$. A typical hydrophone beam pattern and frequency response curve is shown in Fig. 12. The hydro-

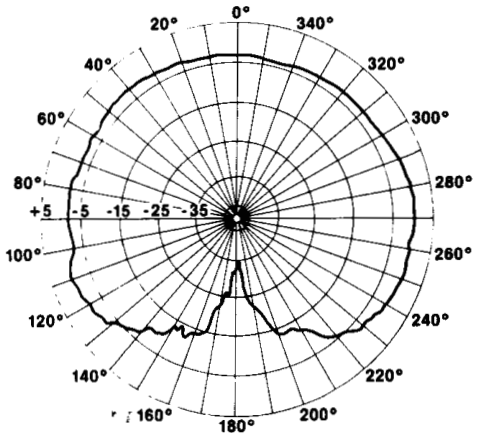

HYDROPHONE BEAM PATTERN

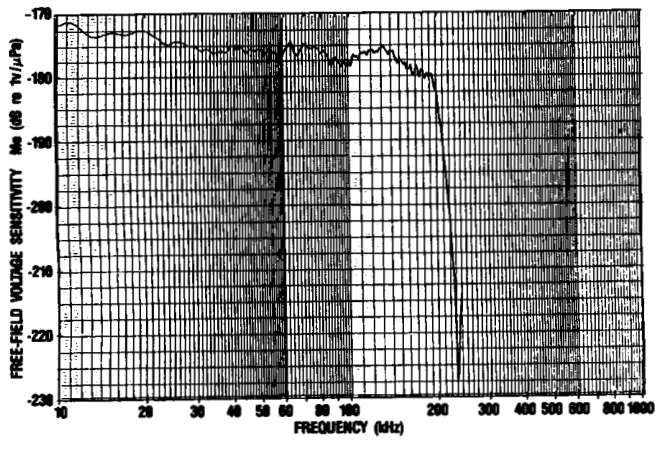

HYDROPHONE FREQUENCY RESPONSE

Fig. 12. Typical beam pattern and frequency response. phones can be positioned at any point along the array arms. 
Fig. 13 is a schematic of the electronic phase locking system. A reference $5 \mathrm{kHz}$ signal derived directly from the source-synthesizers phase locks the tower receiver-synthesizers to the source and sample frequency synthesizers. The phase locking system assures that the measured signal characteristics are due to the environment and are not instrumentation effects.

Control of the receiving systems is through the use of a shipboard terminal and a subsurface computer. Keyboard inputs leave via a RS 232 port and are converted to frequency shift keying (FSK) signals by an interface unit. These signals are then transmitted through the umbilical cable to the subsurface data acquisition unit. The subsurface interface unit then converts the FSK signals back to the proper direct current (dc) levels to communicate with the computer. Control links from the computer to the various units provide control signals to make changes ordered at the shipboard terminal.

System status data from several sensors are digitized and sent to the multiplexing unit. These data are frequency modulated and transmitted up the umbilical cable to the shipboard demultiplexing unit. There they are converted to a digital signal and passed through the FSK interface card, which adjusts the signal levels for correct inputs to the terminal. Fig. 14 shows a simplified block diagram of this control system.

\section{BotTOM Backscattering ResUlts}

In the first of a series of planned experiments, this instrumentation was used to collect bottom backscattering data in a flat, homogeneous, and isotropic area 19 miles south of Panama City, Florida [7]. Bottom backscattering measurements were made as a function of frequency $(20-180 \mathrm{kHz})$, grazing angle $\left(5-30^{\circ}\right)$, and environmental conditions. Sidescan sonar, underwater television, stereo photography, highresolution bathymetry, and sediment core analysis were used to select and classify the experimental area.

The multiplexed signal containing data from 16 spatially separated hydrophones was recorded on a Honeywell Model 101 analog tape recorder. The multiplexed signal was demodulated and the narrow-band outputs, centered at $5 \mathrm{kHz}$, were filtered, amplified, and converted and a mean backscattering strength was estimated for each set of ensemble-averaged data records.

The mean backscattering strength $(B S)$, in $\mathrm{dB}$ re $1 \mathrm{~m}^{2}$, was calculated using the following equation:

$$
B S=R L-S L+2 T L-10 \log A
$$

where

$B S$ scattering strength in $\mathrm{dB}$ re $1 \mathrm{~m}^{2}$,

$R L$ received level in $\mathrm{dB}$ re $1 \mu \mathrm{Pa}$,

$S L$ source level in $\mathrm{dB}$ re $1 \mu \mathrm{Pa}$ at $1 \mathrm{~m}$ along the maximum response axis,

$T L$ transmission loss in $\mathrm{dB}$,

$A$ effective insonified bottom area in $\mathrm{m}^{2}$.

Since the beampattern of the parametric sources were circularly symmetric, the effective insonified areas were the areas of the projection of the circular area at the $3 \mathrm{~dB}$ down

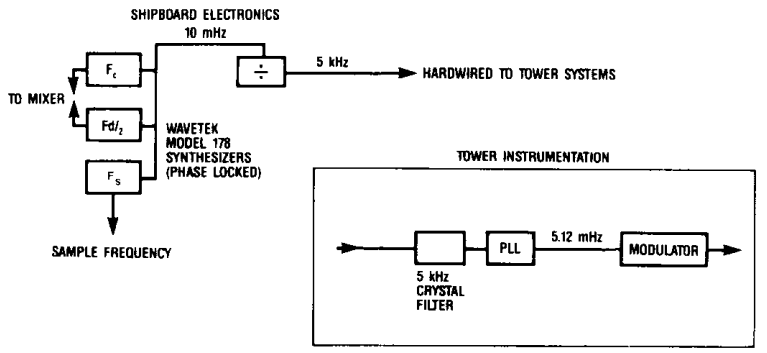

Fig. 13. Phase locking system.

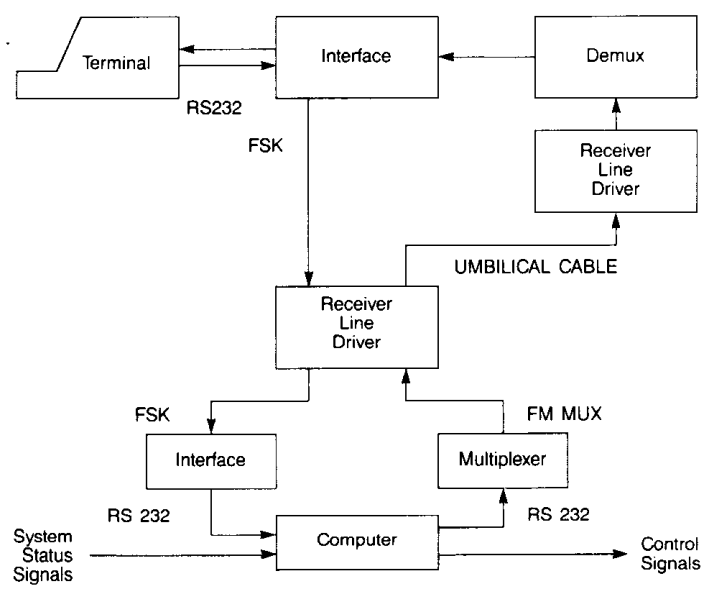

Fig. 14. Receiving control system.

points of the main beam where it intersects the bottom. This assumes that the grazing angle is constant over the instantaneous area. This is acceptable because the linear sound speed profiles, which were present during the experiment, did not produce any focusing or shadowing in the measurement areas. In cases where the area was pulse-length limited, the area was defined as

$$
A=r \beta\left(\left(c_{b} \tau / 2\right) \sec \theta_{g}\right)
$$

where

$r$ horizontal range,

$c_{b}$ sound speed just above the bottom,

$\tau$ pulse length,

$\beta$ effective beam width of the projector and receiving hydrophone,

$\theta_{g}$ grazing angle.

Bottom backscattering can also be expressed as [1]

$$
B S=10 \log \mu+10 \log \sin ^{2} \theta_{g} \text { (Lambert's law) }
$$

where $10 \log \mu=$ backscattering strength at normal incidence if Lambert's law is satisfied.

Figs. 15 and 16 show samples of data from the Panama City experiments [7]. Fig. 15 shows scattering strength estimates as a function of grazing angle for frequencies of $20,40,60$, and $90 \mathrm{kHz}$. A $\sin ^{2} \theta_{g}$ curve was fitted to these data, suggesting that the grazing angle dependence follows Lambert's law. Fig. 


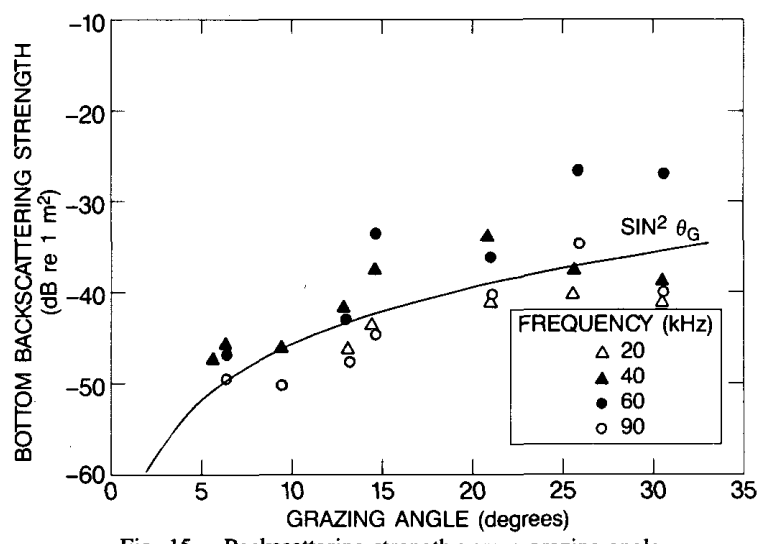

Fig. 15. Backscattering strength versus grazing angle.

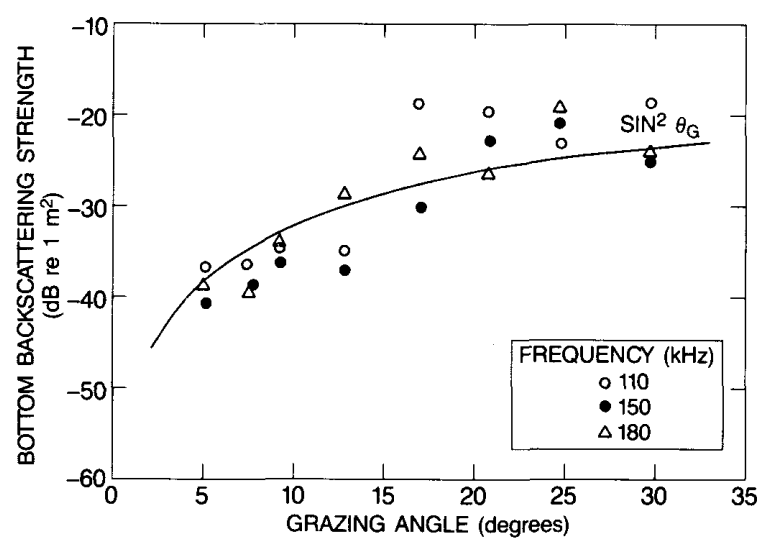

Fig. 16. Backscattering strength versus grazing angle.

16 gives the high-frequency scattering strength estimates $(110$, $150,180 \mathrm{kHz}$ ) versus grazing angle. These values tend to show the same general functional characteristics as the lowerfrequency scattering strength estimates. Reference [7] fully describes the results of this experiment.

\section{SUMMARY}

NORDA has developed a high-frequency acoustic measurement system for use in shallow water. The heart of the system is a pair of submersible towers that support acoustic sources, receiving arrays, and control electronics. The system has been used to obtain bottom backscattering data at frequencies from 20 to $180 \mathrm{kHz}$.

\section{ACKNOWLEDGMENT}

We thank L. Carlton and W. Clay at the Naval Underwater Systems Center, New London, CT, for development of the parametric acoustic sources used in the systems, and P. Blanchard and D. Sherman at Petro-Marine Engineering, Gretna, LA, for design and construction of the acoustic towers.

\section{REFERENCES}

[1] R. J. Urick, Principles of Underwater Sound. New York: McGraw-Hill, 1975.
[2] H. K. Wong and W. D. Chesterman, "Bottom backscattering near grazing incidence in shallow water," J. Acoust. Soc. Amer., vol. 44, pp. $1713-1718,1968$.

[3] C. M. McKinney and C. D. Anderson, "Measurements of backscattering of sound from the ocean bottom,"'J. Acoust. Soc. Amer., vol. 36, pp. 158-163, 1969.

[4] H. Boehme, N. P. Chotiros, L. O. Rolleigh, S. P. Pitt, A. L. Garcia, T. G. Goldsberry, and R. A. Lamb, "Acoustic backscattering at low grazing angles from the ocean bottom-Part I: Bottom backscattering strength," J. Acoustic Soc. Amer., vol. 77, pp. 962-974, 1985.

[5] H. Boehme, N. P. Chotiros, and M. P. Churay, "Bottom acoustic backscattering at low grazing angles in shallow water-Part I: Bottom backscattering strength," in Scattering Phenomena in Underwater Acoustics, Proc. Int. Acoust., vol. 7, pp. 19-26, 1985.

[6] W. I. Roderick and R. K. Dullea, High Resolution Bottom Backscattering Measurements, Naval Underwater Systems Center, NUSC Technical Document 7181, 1984.

[7] S. Stanic, K. B. Briggs, P. Fleischer, R. I. Ray, and W. B. Sawyer, "Shallow-water high-frequency bottom scattering off Panama City, Florida," J. Acoust. Soc. Amer., to be published.

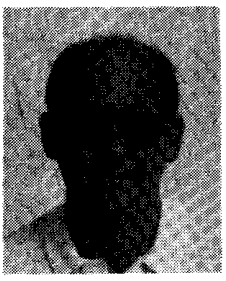

Steve Stanic was born in Montreal, Que., Canada on August 2, 1944. In 1967 he received the B.S. degree in mathematics and physics from Sir George Williams University in Montreal. He received the M.S. degree in aerospace engineering and the Ph.D. degree in physics from The Pennsylvania State University, University Park, in 1970 and 1976 respectively.

From 1977 to 1980 he was a Research Associate at the Applied Research Laboratory of The Pennsylvania State University. He is currently a Research

Physicist for the Naval Ocean Research and Development Activity at the National Space Technology Laboratory in Mississippi. From 1987 to 1988 he was a Visiting Scholar in the Department of Electrical Engineering and Computer Science at the University of California, San Diego.

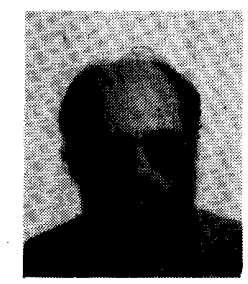

Bruce E. Eckstein was born in Olean, New York, on October 29, 1949. He received the B.S. degree in ocean engineering from Florida Atlantic University, Boca Raton, in 1971. He received the B.S degree in electrical engineering from Florida Atlantic University in 1975 .

From 1971 to 1974 he worked as a Seismic Engineer for Seismic Explorations International S.A. From 1974 to 1976 he worked for the U.S. Army. From 1976 to the present he has worked for ity, National Space Technology Laboratory, of the U.S. Navy. the Naval Ocean Research and Development Activ-

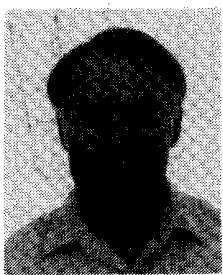

Robert L. Williams was born in Memphis, Tennessee, on November 8,1938 . He received the B.S. degree in combined sciences from the University of Southern Mississippi, Hattiesburg, in 1960.

He worked as a civilian Electronics Instructor for the U.S. Air Force in various radar and communication systems from 1962 until 1980. From 1980 to the present he has worked as an Electronic Technician for the Advanced Technology Branch of the Ocean Technology Division of the Naval Ocean Research and Development Activity at the National 


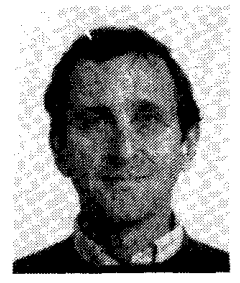

Peter Fleischer was born in Coburg, Germany, on September 10, 1941. He received the B.A. degree in geology (cum laude) from the University of Minnesota, Minneapolis, in 1963, and the Ph.D. degree in marine geology from the University of Southern California, Los Angeles, in 1970.

During 1970-1971 he held a NSF-sponsored Postdoctoral Fellowship at the Duke University Marine Laboratory. From 1971 to 1978 he was on the faculty of the Institute of Oceanography at Old Dominion University, Norfolk, VA. Since 1978 he has been a Principal Investigator with the Seafloor Geosciences Division a the Naval Ocean Research and Development Activity, National Space Technology Laboratory. His research interests are in acoustic characterization of the sea floor, sidescan sonar applications, marine sedimentation, and continental margin geology.

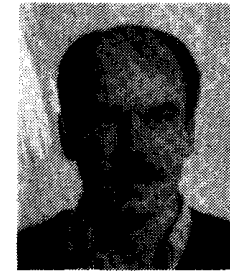

Kevin B. Briggs was born in Montgomery, Alabama, on December 20, 1954. He received the B.S. degree in biology from Florida Atlantic University, Boca Raton, in 1975 and the M.S. degree in zoology from the University of Georgia, Athens, in 1978.

Since joining the Naval Ocean Research and Development Activity at the National Space Technology Laboratory in Mississippi in 1979, he has been engaged in research on geoacoustic and roughness properties of the sea floor. 